\title{
Enhanced Awareness Indicated by Detection Ratio of Dementia with Community-based Active Survey
}

\author{
Yun-Ru Lu \\ China Medical University Hospital \\ Ya-Chung Jeng \\ National Taiwan University Hospital Yun Lin Branch \\ Wen-Yuan Lee \\ China Medical University Hospital \\ Wei-Chih Hsu \\ Shin Kong Wu Ho Su Memorial Hospital \\ Amy Ming-Fang Yen \\ Taipei Medical University \\ Shin-Liang Pan \\ National Taiwan University Hospital \\ Yen-Ching Chen \\ National Taiwan University \\ Sam Li-Sheng Chen ( $\sim$ samchen@tmu.edu.tw) \\ Taipei Medical University \\ Hsiu-Hsi Chen \\ National Taiwan University \\ Horng-Huei Liou \\ National Taiwan University Hospital Yun Lin Branch \\ Tzy-Haw Wu \\ National Taiwan University Hospital
}

\section{Research}

Keywords: Dementia, Early detection, Prevalence, Incidence

Posted Date: January 2nd, 2020

DOI: https://doi.org/10.21203/rs.2.19887/v1

License: (1) (1) This work is licensed under a Creative Commons Attribution 4.0 International License. Read Full License 


\section{Abstract}

Background: Little is known about how early awareness is enhanced via a community-based active detection of dementia in comparison with the passive detected dementia through routine clinical practice.

Methods: To assess the extent of the awareness, the adjusted detection ratio, the ratio of prevalence to incidence was developed by a Bayesian regression model based on a sample of 183 participants from community-based active survey and 1,921,308 subjects from clinical practice.

Results: Given $2.91 \%$ prevalence estimated from passive detection and $6.59 \%$ prevalence on active survey, and $1.83 \%$ incidence for those aged 65 years or older, the detection ratios were higher in active survey than passive detection for those aged 65-79 years (4.23, $95 \%$ Cl: 2.68-6.69) versus (1.45, 95\% Cl: 1.43-1.47). Similar findings were also observed for those aged 80 years

Conclusions: Active community-based detection was approximately three times that of passive detection due to the enhanced awareness of early detection of dementia.

Keywords: Dementia; Early detection; Prevalence; Incidence

\section{Background}

To gain a better understanding of awareness of dementia play an important role in early diagnosis and treatment of dementia. Developing an indicator for such a purpose is helpful for the reflection of the extent of awareness in the underlying population. The simple indicator of prevalence to incidence (detection ratio) was useful in neuroepidemiological study. Incidence rate is a fundamental measurement related to the etiology of the disease whereas prevalence is affected by patients' behavior related to awareness and early detection. For example, by using this indicator, women are more likely to seek medical attention than men from a door-to-door survey of Parkinson disease[1].

A wide range of dementia prevalence from $1.8-10.5 \%[2,3,4,5]$ among different countries in the elderly aged 65 and older was noted. The variation of incidence across countries still exists but seems smaller than that of prevalence. The combined both figures in terms of the ratio of prevalence to incidence may provide a good indicator for awareness of detecting dementia and health care quality for treating dementia patients. It is postulated that higher detection ratio was attributed to the earlier diagnosis through active detection based on a community-based survey.

We aimed to estimate the detection ratio of dementia by age and gender using the prevalence of dementia obtained from a community-based active survey and incident dementia estimated through population-based health-insurance-registry.

\section{Methods}

\section{Study design}

The cross-sectional study design for estimating the prevalence of dementia was conducted by active community-based survey and by passive survey through routine clinical practice. Additionally, a prospective cohort study was conducted, following a normal cohort with free of dementia over time, to identify newly incident cases based on a population-based health-insurance-registry data to ascertain the incidence of dementia.

\section{Data sources}

There are two data sources for estimating the prevalence of dementia by different detection methods that are described as follows.

\section{Passive survey for dementia (Population-health-insurance-registry)}

The first data for estimating prevalence were based on data derived from the National Health Insurance (NHI) system in Taiwan initiated since 1995. It has covered more than $99 \%$ of the total population [6] and approximately $97 \%$ of hospitals and clinics have contracted with the NHI [7]. In addition to the utilization of the NHI database for public policy use, this dataset can be dealt with a 
longitudinal follow-up national cohort embracing 23 million insured people. The dataset covered information on all medical service, such as ambulatory care claims, inpatient claims, and prescriptions [8].

Data from medical records of patients with dementia who had visited health service locations during the period from 2000 to 2003 were computerized and is conceptualized as a passive survey for detecting dementia among the underlying Taiwanese population.

\section{Active survey for dementia (Community-based survey on dementia)}

To estimate the prevalence of dementia though active detection method, an active survey with three-phase design was conducted. Subjects in this study were derived from a community-based integrated screening program in 2013 in Tainan, the southern area of Taiwan. A total of 183 participants were enrolled in our investigation.

\section{Instruments in active survey}

The Chinese versions of the Mini Mental State Examination (MMSE) and AD8 questionnaire [9] were used. The details of assessing the performance of MMSE and AD8 described as follows. The MMSE is a brief test of mental status. The score on MMSE ranges from 0 to 30 with lower values indicative of greater cognitive impairment. The AD8 is a brief, sensitive screening tool that reliably differentiates between dementia and non-dementia at the very mild stage. The score on AD8 was range from 0 to 8 with higher values indicative of greater cognitive impairment.

\section{Procedures in active survey}

The procedures of the three-phase study design is composed of three steps: (1) Step1: The AD8 screening questionnaire is a brief informant-based measure used by participants (2) Step2: The Chinese versions of the MMSE used by psychologist (3) Step3: The participants was diagnosed by neurologists using the NIA-AA (National Institute on Aging Alzheimer's Association) guideline in 2011: Criteria for all-cause dementia. There are total 6 psychologist and 3 neurologists participated in the screening.

\section{Measurements for cognitive status in active survey}

The cut point of MMSE was 21 for distinguishing dementia or not. The cut point of AD8 for distinguishing dementia cases was greater than 2 in all age group.

\section{Data used for ascertaining incident dementia}

In addition to estimating the prevalence of dementia by different detection methods, we also estimated incidence by identifying a normal cohort after excluding those with preexisting dementia in the year of 2000 based on a population-based health-insurance registry data. The cohort study design began at the year of 2000. We followed the normal cohort free of dementia from 2000 to 2003 to identify newly diagnosed (incident) cases. We used International Classification of Diseases, Ninth Revision, Clinical Modification (ICD-9-CM) and prescription codes to identify dementia patients from the NHI database. Total of 99,609 incident cases were diagnosed with dementia (ICD-9-CM code 290, 290.40, 331.0). The total follow-up person-years were 5,445,586.

\section{Data Collection}

Regarding active community-based survey, we collected all information on the variables involved with three phases, which included demographic characteristics, the scores of AD8, the scores of MMSE, and the clinical diagnosis of dementia. For the passive survey data, we collected data on age, gender, location of clinic visit, date of clinic visit and date of diagnosis. Most patients with dementia would visit their neurologist at least annually.

\section{Statistical analysis}

We first estimated age-gender-specific prevalence based on the cross sectional data in the year of 2000. We also estimated the prevalence of dementia based on a community based survey to represent the prevalence dementia through early detection. We estimated the incidence rate of dementia based on a cohort that was dementia-free at entry to the study (2000) and followed them up until the end of 2003. To identify newly diagnosed cases, we computed person-years based on the underlying population at risk. The age specific incidence of dementia during the period 2000-2003 was calculated as the number of new cases of dementia divided by the number of person-years at risk given as 5 -year age band starting at age 65 years. The numbers of person-years contributed by each subject who had no dementia was calculated by the time from taking the time between the date of entry into study and the date 
of the end of study. For subjects with dementia the numbers of person-years was calculated by the time from the date at entry of study to the date of first diagnosed as dementia, the date of death for subjects who were dead before the end of follow-up, or the date of the end of study, whichever came first. The effects of age, gender, and geographic areas on the incidence of dementia were assessed by using a multi-variable Poisson regression model.

The detection ratio was estimated by using both prevalence and incidence figures. For adjusting the detection ratio for dementia, the Bayesian method was developed and given the premise that prevalence follows a Binominal distribution and incidence follows a Poisson distribution. Based on the framework of generalized linear model, the relationship between the detection ratio and the covariates of interest, e.g. age, gender, and geographic area was regressed through a logarithm link function. After assessing the interaction terms in Bayesian regression model, a strong interaction between age and gender was noted. Therefore, the models stratified by gender are presented. For a better understanding of the difference of detection ratios between passive and active survey, we also developed a Bayesian regression model making allowance for estimating the detection ratios of two survey methods.

\section{Results}

Table 1 shows age-specific prevalence and incidence of dementia estimated from both population-health-insurance-registry-based data and active community-based survey in Taiwan. The overall prevalence rate for subjects aged 65 years and older was $2.9 \%$ from the former database, which was lower than $9.29 \%$ estimated from a community-based survey. Age-specific prevalence rate increased with age, being double in every five-year age band until 80 years of age, and soared up to approximately $20 \%$ in the eldest category (90+). The similar prevalence trend but only two age bands was estimated from a community-based survey. 
Table 1

Age and gender specific prevalence and incidence rate of dementia

\begin{tabular}{|c|c|c|c|c|c|c|c|c|}
\hline Gender & Age & $\begin{array}{l}\text { Prevalent } \\
\text { Case }\end{array}$ & $\begin{array}{l}\text { Total } \\
\text { Population }\end{array}$ & $\begin{array}{l}\text { Prevalence } \\
\%\end{array}$ & $\begin{array}{l}\text { Incident } \\
\text { case }\end{array}$ & $\begin{array}{l}\text { Person } \\
\text { years }\end{array}$ & $\begin{array}{l}\text { Incidence } \\
\%\end{array}$ & $\begin{array}{l}\text { Detection ratio } \\
\text { (Prevalence/Incidence) }\end{array}$ \\
\hline \multirow[t]{6}{*}{ Male } & $65-69$ & 2620 & 333391 & 0.79 & 5757 & 983219 & 0.59 & 1.34 \\
\hline & $70-74$ & 4247 & 326658 & 1.3 & 10349 & 948879 & 1.09 & 1.19 \\
\hline & $75-79$ & 6000 & 205981 & 2.91 & 13622 & 575801 & 2.37 & 1.23 \\
\hline & $80-84$ & 6564 & 94920 & 6.92 & 11009 & 248459 & 4.43 & 1.56 \\
\hline & $85-89$ & 5041 & 38710 & 13.02 & 6279 & 93985 & 6.68 & 1.95 \\
\hline & $90+$ & 3445 & 11363 & 30.32 & 2278 & 23246 & 9.8 & 3.09 \\
\hline Subtotal & & 27917 & 1011023 & 2.76 & 49774 & 2873587 & 1.73 & 1.6 \\
\hline \multirow[t]{6}{*}{ Female } & $65-69$ & 2850 & 325651 & 0.88 & 5803 & 960760 & 0.6 & 1.47 \\
\hline & $70-74$ & 5203 & 255964 & 2.03 & 8976 & 742221 & 1.21 & 1.68 \\
\hline & $75-79$ & 7198 & 172188 & 4.18 & 11695 & 481181 & 2.43 & 1.72 \\
\hline & $80-84$ & 6481 & 93801 & 6.91 & 11098 & 245000 & 4.53 & 1.53 \\
\hline & $85-89$ & 4101 & 45555 & 9 & 7730 & 109449 & 7.06 & 1.27 \\
\hline & $90+$ & 2132 & 17126 & 12.45 & 4563 & 33389 & 13.67 & 0.91 \\
\hline Subtotal & & 27965 & 910285 & 3.07 & 49865 & 2571999 & 1.94 & 1.58 \\
\hline \multirow[t]{6}{*}{ All } & $65-69$ & 5470 & 659042 & 0.83 & 11560 & 1943978 & 0.59 & 1.41 \\
\hline & $70-74$ & 9450 & 582622 & 1.62 & 19325 & 1691100 & 1.14 & 1.42 \\
\hline & $75-79$ & 13198 & 378169 & 3.49 & 25317 & 1056982 & 2.4 & 1.45 \\
\hline & $80-84$ & 13045 & 188721 & 6.91 & 22107 & 493459 & 4.48 & 1.54 \\
\hline & $85-89$ & 9142 & 84265 & 10.85 & 14009 & 203434 & 6.89 & 1.57 \\
\hline & $90+$ & 5577 & 28489 & 19.58 & 7291 & 56635 & 12.87 & 1.52 \\
\hline Total & & 55882 & 1921308 & 2.91 & 99609 & 5445586 & 1.83 & 1.59 \\
\hline \multicolumn{9}{|c|}{$\begin{array}{l}\text { Active Survey } \\
\text { Data }\end{array}$} \\
\hline & $65-79$ & 11 & 135 & $8.15^{\star}$ & 56202 & 4692060 & 1.2 & 6.79 \\
\hline & $\begin{array}{l}80- \\
90+\end{array}$ & 6 & 51 & $11.76^{*}$ & 43407 & 753528 & 5.76 & 2.04 \\
\hline & total & 17 & 183 & $9.29^{*}$ & 99609 & 5445586 & 1.83 & 5.08 \\
\hline
\end{tabular}

Following a normal fixed cohort from the year 2000 (excluding those who had dementia before 2000), 99,609 incident dementia were ascertained during the follow-up period from 2000 to 2003 . The incidence rate of total dementia was $1.83 \%$. Incidence rate of dementia increased with age, doubling in every 5 -year age bands similarly seen in the figures of prevalence. The incidence of dementia was approximately 19 times higher among persons older than 90 years compared with those between 65 and 69 years of age. The gender-specific incidence was slightly higher in females (19.4\%o) than males $(17.3 \%$ ). 
As mentioned in methodology, the detection ratio enabled us to assess the extent of awareness of detecting dementia. The agespecific active detection ratio of dementia are presented in the last column of Table 1. Using the national figures from NHI (passive survey data), the overall detection ratio for dementia was 1.53 years in our study. The older the age of dementia, the detection ratio was larger. In contrast, the detection ratios based on a community-based survey (active survey) were larger than those estimated form the NHI data

We also compared age-specific incidence rate of dementia in four main areas in Taiwan, we found there was difference across four areas of Taiwan. It seems that north Taiwan has higher incidence rate than east Taiwan. The finding suggests urban area had higher incidence rate of dementia than rural area in Taiwan. Table 2 shows the effects of age, gender, area on the risk of incidence rate of dementia by univariate and multivariate Poisson regression model. The results show that age, gender and geographic area were associated with dementia.

Table 2

Effects of Age, gender, geographic on the risk of incidence rate of dementia by Poisson regression model

\begin{tabular}{|lllll|}
\hline Variable & Univariate & \multicolumn{3}{l|}{ Multivariate } \\
\cline { 2 - 5 } & RR $(95 \% \mathrm{Cl})$ & P-value & RR $(95 \% \mathrm{Cl})$ & P-value \\
\hline Age & & $<.0001$ & & $<.0001$ \\
\hline $65-69$ & 1.00 & 1.00 & \\
\hline $70-74$ & $1.02(0.99,1.04)$ & $1.01(0.99,1.04)$ & \\
\hline $75-79$ & $1.03(1.01,1.06)$ & $1.03(1.01,1.05)$ & \\
\hline $80-84$ & $1.05(1.03,1.08)$ & $1.05(1.03,1.07)$ & \\
\hline $85-89$ & $1.09(1.06,1.12)$ & $1.09(1.06,1.12)$ & \\
\hline $90+$ & $1.14(1.11,1.18)$ & & $1.14(1.11,1.18)$ & \\
\hline Gender & $1.01(1.00,1.02)$ & 0.2003 & $1.01(1.00,1.03)$ & 0.0450 \\
\hline Area & & 0.0057 & & 0.0146 \\
\hline Central & 1.00 & & 1.00 & \\
\hline North & $1.02(1.00,1.04)$ & & $1.01(1.00,1.04)$ & \\
\hline South & $1.00(0.98,1.01)$ & & $0.99(0.98,1.02)$ & \\
\hline East & $1.03(0.99,1.07)$ & & $1.02(0.97,1.06)$ & \\
\hline
\end{tabular}

Table 3 shows the adjusted detection ratios of dementia. After adjusting for area, the detection ratio increased from 1.20 (95\% Confidence Interval (Cl)1.15-1.24) for 70-74 age group to 3.27 (95\% $\mathrm{Cl} 3.13-3.41)$ for 90 + age group in males. The $1.45(95 \% \mathrm{Cl}$ 1.41-1.49) of detection ratio was higher in northern area than three other areas in males as shown in Table 3 . The opposite results were noted for females with the detection ratio decreasing from $1.69(95 \% \mathrm{Cl} 1.63-1.74)$ for $70-74$ age group to 0.90 (0.86-0.94) for $90+$ age group after adjusting area. The detection ratios in females were higher than males in all areas. 
Table 3

Adjusted detection ratios of dementia measured by passive survey

\begin{tabular}{|c|c|c|}
\hline Variables & $\begin{array}{l}\text { Regression Coefficient } \\
(2.5 \%, 97.5 \%)\end{array}$ & $\begin{array}{l}\text { Adjusted Detection Ratios } \\
(2.5 \%, 97.5 \%)\end{array}$ \\
\hline \multicolumn{3}{|l|}{ Male } \\
\hline Intercept & $0.197(0.145,0.248)$ & \\
\hline \multicolumn{3}{|l|}{ Age } \\
\hline $65-69$ & baseline & $1.35(1.29,1.41)$ \\
\hline $70-74$ & $-0.12(-0.176,0.063)$ & $1.20(1.15,1.24)$ \\
\hline $75-79$ & $-0.091(-0.145,0.037)$ & $1.23(1.19,1.27)$ \\
\hline $80-84$ & $0.141(0.087,0.195)$ & $1.55(1.51,1.60)$ \\
\hline $85-89$ & $0.36(0.304,0.417)$ & $1.93(1.86,2.00)$ \\
\hline $90+$ & $0.886(0.823,0.949)$ & $3.27(3.13,3.41)$ \\
\hline \multicolumn{3}{|l|}{ Area } \\
\hline Central & baseline & $1.20(1.17,1.24)$ \\
\hline North & $0.186(0.15,0.222)$ & $1.45(1.41,1.49)$ \\
\hline South & $0.096(0.056,0.136)$ & $1.32(1.29,1.37)$ \\
\hline East & $-0.322(-0.417,0.228)$ & $0.87(0.80,0.96)$ \\
\hline \multicolumn{3}{|l|}{ Female } \\
\hline Intercept & $0.251(0.2,0.302)$ & \\
\hline \multicolumn{3}{|l|}{ Age } \\
\hline $65-69$ & baseline & $1.47(1.41,1.54)$ \\
\hline $70-74$ & $0.137(0.082,0.191)$ & $1.69(1.63,1.74)$ \\
\hline $75-79$ & $0.152(0.1,0.205)$ & $1.71(1.66,1.76)$ \\
\hline $80-84$ & $0.032(-0.021,0.085)$ & $1.52(1.47,1.57)$ \\
\hline $85-89$ & $-0.148(-0.204,0.091)$ & $1.27(1.22,1.32)$ \\
\hline $90+$ & $-0.492(-0.557,0.428)$ & $0.90(0.86,0.94)$ \\
\hline \multicolumn{3}{|l|}{ Area } \\
\hline Central & baseline & $1.37(1.32,1.41)$ \\
\hline North & $0.211(0.175,0.247)$ & $1.69(1.64,1.73)$ \\
\hline South & $0.025(-0.015,0.066)$ & $1.40(1.60,1.44)$ \\
\hline East & $0.889(0.807,0.97)$ & $3.32(3.07,3.59)$ \\
\hline
\end{tabular}

Table 4 shows the adjusted detection ratios for passive survey and active survey. Active detection ratios increased from $1.45(95 \% \mathrm{Cl}$ 1.43-1.47) for 65-79 age group to $1.64(95 \% \mathrm{Cl} 1.61-1.66)$ for 80 + age group in passive survey. Active detection ratios increased from $4.23(95 \% \mathrm{Cl} 2.68-6.69)$ for $65-79$ age group to $4.77(95 \% \mathrm{Cl} 3.02-7.54)$ for $80+$ age group in active survey. 
Table 4

Adjusted detection ratios of dementia in comparison between passive and active survey

\begin{tabular}{|lll|}
\hline Variables & $\begin{array}{l}\text { Regression Coefficient } \\
(2.5 \%-97.5 \%)\end{array}$ & $\begin{array}{l}\text { Adjusted Detection Ratios } \\
(2.5 \%-97.5 \%)\end{array}$ \\
\hline Intercept & $0.252(0.220,0.283)$ & \\
\hline Age 65-79 vs. Age 80+ & $0.120(0.100,0.140)$ & \\
\hline Active Survey vs. Passive Survey & $1.071(0.614,1.530)$ & \\
\hline & & $1.45(1.43,1.47)$ \\
\hline Passive Survey & & $1.64(1.61,1.66)$ \\
\hline Age 65-79 & & \\
\hline Age 80+ & & $4.23(2.68,6.69)$ \\
\hline
\end{tabular}

The detection ratio of dementia in our study were also compared with other community studies. Table 5 shows the prevalence, incidence, and ratio of dementia in Taiwan and other community-based studies. Generally speaking, these community-based survey led to active detection of dementia as the majority of detection ratio was higher than 3 in contrast to only 1.59 in the current passive survey. It is also very interesting to note that the earlier the era like the Denmark and Sweden study the lower the detection ratio. However, different diagnosis criteria in in different periods may also account for this disparity. 
Table 5

Prevalence, incidence, and ratio of dementia in Taiwan and other community-based studies

\begin{tabular}{|c|c|c|c|c|c|c|c|c|}
\hline Study & $\begin{array}{l}\text { Study } \\
\text { Period/ } \\
\text { Countries }\end{array}$ & $\begin{array}{l}\text { Age } \\
\text { Range }\end{array}$ & $\begin{array}{l}\text { N for } \\
\text { Prevalence } \\
\text { study }\end{array}$ & $\begin{array}{l}\mathbf{N} \text { for } \\
\text { Incidence } \\
\text { study }\end{array}$ & Area & $\begin{array}{l}\text { Prevalence } \\
\%\end{array}$ & $\begin{array}{l}\text { Incidence } \\
\%\end{array}$ & $\begin{array}{l}\text { Detection ratio } \\
\text { (Prevalence/Incidence) }\end{array}$ \\
\hline $\begin{array}{l}\text { Current } \\
\text { (Passive } \\
\text { survey) }\end{array}$ & $\begin{array}{l}2000 \sim \\
2003 / \\
\text { Taiwan }\end{array}$ & $65+$ & 1921308 & 1921308 & Urban/Rural & 2.91 & 1.83 & 1.59 \\
\hline $\begin{array}{l}\text { Current } \\
\text { (Active } \\
\text { survey) }\end{array}$ & $\begin{array}{l}\text { 2013/ } \\
\text { Taiwan }\end{array}$ & $65+$ & 183 & 1921308 & Rural & 9.29 & 1.83 & 5.08 \\
\hline $\begin{array}{l}\text { Chen et al. } \\
{[18]}\end{array}$ & $\begin{array}{l}\text { 2004/ } \\
\text { Taiwan }\end{array}$ & $65+$ & 1308 & 1921308 & Urban/Rural & 10.55 & 1.83 & 5.77 \\
\hline $\begin{array}{l}\text { Sun et al. } \\
\text { [19] }\end{array}$ & $\begin{array}{l}2011 \sim \\
\text { 2013/ } \\
\text { Taiwan }\end{array}$ & $65+$ & 10432 & 1921308 & Urban/Rural & 8.14 & 1.83 & 4.45 \\
\hline $\begin{array}{l}\text { Andersen } \\
\text { et al.[12] }\end{array}$ & $\begin{array}{l}1985 \sim \\
\text { 1993/ } \\
\text { Denmark }\end{array}$ & $\begin{array}{l}65- \\
84\end{array}$ & 3299 & 3086 & Urban & 7.10 & 2.95 & 2.40 \\
\hline $\begin{array}{l}\text { Yoshitake } \\
\text { et al. [13] }\end{array}$ & $\begin{array}{l}\text { 1985/ } \\
\text { Japan }\end{array}$ & $65+$ & 887 & 826 & Sub-rural & 6.7 & 1.8 & 3.72 \\
\hline $\begin{array}{l}\text { Fratiglioni } \\
\text { et al. [14] }\end{array}$ & $\begin{array}{l}1987 / \\
\text { Sweden }\end{array}$ & $75+$ & 1810 & 1473 & Urban & 13.2 & 4.00 & 3.30 \\
\hline $\begin{array}{l}\text { Fillenbaum } \\
\text { et al. [15] }\end{array}$ & $\begin{array}{l}1986 \text { } \\
1987 / \\
\text { USA }\end{array}$ & $\begin{array}{l}68+ \\
/ 65+{ }^{*}\end{array}$ & 363 & 1093 & Urban/Rural & 7.10 & 1.93 & 3.68 \\
\hline $\begin{array}{l}\text { Di Carlo et } \\
\text { al.[16] }\end{array}$ & $\begin{array}{l}1992 \text { } \\
1993 / \\
\text { Italy }\end{array}$ & $\begin{array}{l}65- \\
84\end{array}$ & 3497 & 3208 & Urban/Rural & 8.26 & 1.33 & 6.20 \\
\hline $\begin{array}{l}\text { Bermejo- } \\
\text { Pareja et } \\
\text { al.[17] }\end{array}$ & $\begin{array}{l}1994 \text { } \\
1995 / \\
\text { Spain }\end{array}$ & $65+$ & 5278 & 3891 & Urban/Rural & 5.79 & 1.28 & 4.52 \\
\hline $\begin{array}{l}\text { Chen et al. } \\
{[20,21]}\end{array}$ & $\begin{array}{l}2001 \sim \\
\text { 2003/ } \\
\text { China }\end{array}$ & $65+$ & 2917 & 1526 & Rural & 7.2 & 1.47 & 4.90 \\
\hline
\end{tabular}

\section{Discussion}

This study, to our knowledge, is the first large scale population-based study of detection ratio of dementia simultaneously estimate the prevalence and incidence of dementia in the same study. Our findings have significant implications for the etiology, patient behavior, infrastructure, and quality of health care for dementia. The detection ratio reflected the extent of enhancing awareness of dementia. The larger the ratio, the better awareness was enhanced. Low awareness of dementia has been ascertained in routine health insurance health care system as the active detection ratio of community-based survey (active detection method) was greater than that of health insurance heath care system (passive detection method). The crude detection ratio in our NHI study and community study were 1.59 and 5.08. The similar findings in adjusted detection ratio were $1.45(95 \% \mathrm{Cl} 1.43-1.47)$ and $4.23(95 \% \mathrm{Cl} 2.68-6.69)$ for aged $65-$ 79 years in our active and passive survey, respectively. The possible cause may be attributed to the unawareness of family members on dementia and led to a delay treatment. Several prospective longitudinal studies have demonstrated serious deficiencies in the healthcare system's ability to recognize dementia and most dementia remains unrecognized in the primary care setting. Persons with mild dementia are more likely to go unrecognized by physicians and family (over $90 \%$ ) than persons with moderate to severe dementia (over 70\%); however, those with early disease hold the best opportunity treated with available medications [10, 11]. This postulate is supported by our findings through a population -insurance - registry-based study that underdiagnosed dementia in contrast to other 
studies based on a community active detection survey like our community-based survey. This invokes the consideration of community-based screening for dementia in order to enhance awareness and also early detection and treatment of dementia in Taiwan.

The detection-ratio-based statistical regression model was developed to estimate the adjusted detection ratio for the reflection of awareness and the quality of care for dementia, making allowance for age, gender, and geographic variation. This novel method takes into account the associated covariates. The application by this model is also very useful for estimating the degree of enhancement in detection of disease when the active method is compared with the passive method.

We also compared the detection ratio in the current study with those of other countries in Table 5. The detection ratios were 2.4 in Denmark [12], 3.72 in Japan [13], 3.30 in Sweden [14], 6.2 in Italy [15], 4.52 in Spain [16], 3.68 in USA [17], and 4.90 in China [2]. The detection ratios between Japan and USA are close to each other due to the similar study periods of investigation. The Denmark and Sweden in the similar study periods reported the shorter active detection ratio than others, possibly because the two studies were conducted in the earlier era and they may not include the mild dementia cases in their investigations. The awareness of early detection of dementia should be lower in two decades ago. The shortest active detection ratio was 2.4 years in Danish population with age between 65 and 84 whereas the longer detection ratio (3.3 years) in Sweden elder population (age over 75) was reported. The inconsistent active detection ratios could be possible due to not only the different age groups of the targeted population but also the different criteria in dementia diagnosis. The diagnostic criteria as DMS-III-R combined with NINCDS-ADRDA was used in Denmark study but only DMS-III-R was used in Sweden study. After 1990, the detection ratios were considerably higher. Most of other high detection ratios studies were based on active community-based survey and had a reflection of high awareness of early detection of dementia.

The difference of detection ratio between males and females is explained by the fact that difference in the incidence between males and females was not substantial before age 90 years of age but the prevalence in young females was higher than males while the opposite results were noted for the old subject from 80 years onwards. This can account for why the detection ratios were higher in young females than the old ones but the opposite was noted for subjects from 80 years onward.

In the study, we have also demonstrated age and gender-specific incidence and prevalence of dementia in Taiwan. Women had an increased risk of dementia than men. The difference may be explained by the greater life expectancy in women with dementia compared with men diagnosed as dementia at the same age.

As age is an independent risk factor for Alzheimer's diseases (AD), people in this age group of 85 or older are highest risk for AD. Jorm et al. documented the exponential rise of dementia with age in a number of prevalence studies [22]. From the age of 65 years, the prevalence double every 5 years. However, our prevalence was considerably lower than other previous studies. The comparisons across studies should be taken with great caution as the majority of studies were based on an active community-based survey rather than based on population-based registry data. This can be supported by the fact that the prevalence of dementia form active community-based survey in our study was raised from $2.91-9.3 \%$, which was close to two other surveys in Taiwan and other studies in Western countries as shown in Table 5. It should be noted that the awareness of dementia might be lower in developed country. Llibre et al. found the lower prevalence in some developing countries, such as China and India. Even through active survey of prevalence, underestimation of the true prevalence of dementia is still possible because they found lower reported scores by informants for heads of household and male participants in in low-income and middle-income countries [23]. It is very interesting to note that the variation of incidence still exists but the disparity of incidence was smaller compared with that prevalence. This suggest the etiology of dementia was not substantially heterogeneous across different racial groups.

\section{Conclusion}

In conclusion, we demonstrated that the detection ratio of the active community-based survey was higher than that of a passive survey obtained from a population-health-insurance-based data. This indicator (detection ratio) provide a new insight into awareness of early detection of dementia in different medical care systems.

\section{Abbreviations}

$\mathrm{Cl}$ 
Confidence Interval

MMSE

Mini-Mental State Examination

$\mathrm{NHI}$

National Health Insurance

\section{Declarations}

\section{Acknowledgments}

The authors thanks the members who helped to collect data in community study.

\section{Authors' contributions}

YRL, YCJ, and THW conceived the project and wrote the manuscript. AMY, SLP, and SLC processed and analyzed the data. YRL, SLP, and HHC collected data. WYL, WCH, YCC, HHC, and HHL contributed to the data interpretation. All authors read and approved the final manuscript.

\section{Funding Sources}

Study Funding: This study was supported by China Medical University Hospital, Taiwan (CMU No. DMR-103-051) and the Ministry of Science and Technology (MOST 107-3017-F-002-003) and Featured Areas Research Center Program within the framework of the Higher Education Sprout Project by the Ministry of Education (MOE) in Taiwan (grant number NTU-107L9003).

\section{Availability of data and materials}

The data generated during this study are included in this article. All raw data used and/or analyzed during the current study are available from the corresponding author on reasonable request.

\section{Ethics approval and consent to participate}

This study was approved by National Taiwan University Hospital (NTUH) Research Ethics Committee

\section{Consent for publication}

Not applicable.

\section{Competing interests}

The authors declare that they have no competing interests.

\section{Authors' information}

Department of Neurology, China Medical University Hospital, No. 360, Neihu Road, Sec 2, Taipei, 114, Taiwan

Yun-Ru Lu

Department of Family Medicine, Taipei Medical University Hospital, No. 250 Wu-Hsing Street, Taipei, 100, Taiwan

Ya-Chung Jeng,

Department of Neurology, China Medical University Hospital , No. 2, Yude Road, Taichung, 40447, Taiwan

Wen-Yuan Lee

Department of Neurology, Shin-Kong WHS Memorial Hospital, No. 95 Wen Chang Road, Taipei, 100, Taiwan

Wei-Chih Hsu

Page $11 / 13$ 
Amy Ming-Fang Yen, Sam Li-Sheng Chen

Department of Physical Medicine and Rehabilitation, National Taiwan University Hospital, No. 1, Jen-Ai Road, Sec 1, Taipei, 100, Taiwan

Shin-Liang Pan

Institute of Epidemiology and Preventive Medicine, College of Public Health, National Taiwan University, No. 17, Hsu Chow Road, Zhongzheng Dist., Taipei, 100, Taiwan

Yen-Ching Chen, Hsiu-Hsi Chen

Department of Neurology, National Taiwan University Hospital, No. 1, Jen-Ai Road, Sec 1, Taipei, 100, Taiwan

Horng-Huei Liou

Department of Internal Medicine, College of Medicine, National Taiwan University, Taipei, Taiwan, No. 1, Jen-Ai Road, Sec 1, Taipei, 100, Taiwan

Tzy-Haw Wu, MD

\section{References}

1. Chen RC, Chang SF, Su CL, et al. Prevalence, incidence, and mortality of PD: a door-to-door survey in llan county, Taiwan. Neurology. 2001 13;57:1679-86

2. Zhang MY, Katzman R, Salmon D, et al. The prevalence of dementia and Alzheimer's disease in Shanghai, China: impact of age, gender, and education. Ann Neurol. 1990;27:428-437.

3. Wang W, Wu S, Cheng X, et al. Prevalence of Alzheimer's disease and other dementing disorders in an urban community of Beijing, China. Neuroepidemiology. 2000;19:194-200.

4. Meguro K, Ishii H, Yamaguchi S, et al. Prevalence of dementia and dementing diseases in Japan: the Tajiri project. Arch Neurol. 2002;59:1109-1114.

5. Lee DY, Lee JH, Ju YS, et al. The prevalence of dementia in older people in an urban population of Korea: the Seoul study. J Am Geriatr Soc. 2002;50:1233-1239.

6. Wen CP, Tsai SP, Chung WS. A 10-year experience with universal health insurance in Taiwan: measuring changes in health and health disparity. Ann Intern Med. 2008;148:258-267.

7. Lai SW, Liao KF, Liao CC, Muo CH, Liu CS, Sung FC. Polypharmacy correlates with increased risk for hip fracture in the elderly: a population-based study. Medicine. 2010;89:295-299.

8. Lai SW, Su LT, Lin CH, Tsai CH, Sung FC, Hsieh DP. Polypharmacy increases the risk of Parkinson's disease in older people in Taiwan: a population-based study. Psychogeriatrics. 2011;11:150-156.

9. Galvin JE, Roe CM, Powlishta KK, et al. The AD8 A brief informant interview to detect dementia. Neurology. 2005;65:559-564.

10. Callahan CM, Hendrie HC, Tierney WM. Documentation and evaluation of cognitive impairment in elderly primary care patients. Ann Intern Med. 1995;122:422-429.

11. Ross GW, Abbott RD, Petrovitch $\mathrm{H}$, et al. Frequency and Characteristics of Silent Dementia Among Elderly Japanese-American MenThe Honolulu-Asia Aging Study. JAMA. 1997;277:800-805.

12. Andersen K, Nielsen H, Lolk A, Andersen J, Becker I, Kragh-Sørensen P. Incidence of very mild to severe dementia and Alzheimer's disease in Denmark The Odense Study. Neurology. 1999;52:85-90.

13. Yoshitake T, Kiyohara Y, Kato I, et al. Incidence and risk factors of vascular dementia and Alzheimer's disease in a defined elderly Japanese population The Hisayama Study. Neurology. 1995;45:1161-1168.

14. Fratiglioni L, Viitanen M, von Strauss E, Tontodonati V, Herlitz A, Winblad B. Very Old Women at Highest Risk of Dementia and Alzheimer's Disease Incidence Data from the Kungsholmen Project, Stockholm. Neurology. 1997;48:132-138.

Page $12 / 13$ 
15. Fillenbaum GG, Heyman A, Huber MS, et al. The prevalence and 3-year incidence of dementia in older Black and White community residents. J Clin Epidemiol. 1998;51:587-95.

16. Di Carlo A, Baldereschi M, Amaducci L, et al. Incidence of dementia, Alzheimer's disease, and vascular dementia in Italy. The ILSA Study. J Am Geriatr Soc. 2002;50:41-48.

17. Bermejo-Pareja F, Benito-León J. Incidence and subtypes of dementia in three elderly populations of central Spain. J Neurol Sci. 2008;264:63-72.

18. Chen TF, Chiu MJ, Tang LY. Institution Type-Dependent High Prevalence of Dementia in Long-Term Care Units Neuroepidemiology. 2007;28:142-149

19. Sun Y, Lee HJ, Yang SC, et al. A Nationwide Survey of Mild Cognitive Impairment and Dementia, Including Very Mild Dementia, in Taiwan. PLoS One. 2014; 9:e100303

20. Chen R, Ma Y, Wilson K et al. A multicentre community-based study of dementia cases and subcases in older people in China-the GMS-AGECAT prevalence and socio-economic correlates. Int J Geriatr Psychiatry. 2012;27:692-702

21. Chen R, Hu Z, Wei L, Ma Y, Liu Z, Copeland JR. Incident dementia in a defined older Chinese population. PLoS One. 2011;6(9):e24817

22. Jorm AF, Korten AE, Henderson AS. The prevalence of dementia: a quantitative integration of the literature. Acta Psychiatr Scand. 1987;76:465-479.

23. Llibre Rodriguez JJ, Ferri CP, Acosta D, et al. Prevalence of dementia in Latin America, India, and China: a population-based crosssectional survey. Lancet. 2008;372:464-74. 